\title{
3-D cohesive finite element model for application in structural analysis of heavy duty composite pavements
}

\author{
Skar, Asmus; Poulsen, Peter Noe
}

Published in:

Construction and Building Materials

Link to article, DOI:

10.1016/j.conbuildmat.2015.10.052

Publication date:

2015

Document Version

Peer reviewed version

Link back to DTU Orbit

\section{Citation (APA):}

Skar, A., \& Poulsen, P. N. (2015). 3-D cohesive finite element model for application in structural analysis of heavy duty composite pavements. Construction and Building Materials, 101, 417-431.

https://doi.org/10.1016/j.conbuildmat.2015.10.052

\section{General rights}

Copyright and moral rights for the publications made accessible in the public portal are retained by the authors and/or other copyright owners and it is a condition of accessing publications that users recognise and abide by the legal requirements associated with these rights.

- Users may download and print one copy of any publication from the public portal for the purpose of private study or research.

- You may not further distribute the material or use it for any profit-making activity or commercial gain

- You may freely distribute the URL identifying the publication in the public portal 


\title{
3-D cohesive finite element model for application in structural analysis of heavy duty composite pavements
}

\author{
Asmus Skar ${ }^{1, *}$ \\ COWI A/S, Parallelvej 2, 2800 Kgs. Lyngby, Denmark \\ Peter Noe Poulsen ${ }^{2}$ \\ Technical University of Denmark, Brovej, Building 118, 2800 Kgs. Lyngby, Denmark
}

\begin{abstract}
The problem of stiffness degradation in composite pavement systems from localized fracture damage in the quasibrittle cement bound granular mixture are today taken into account only by empirical formulas. These formulas deals with a limited number of materials in a restricted range of design options and would yield unrealistic results in ultimate loading conditions. Cohesive modelling is one of the primary methods to handle localized damage in quasi-brittle materials, e.g., concrete, describing the potential crack in a discrete manner. To increase the versatility of existing methods this paper presents a numerical analysis of the fracture behaviour of cement bound granular mixtures in composite concrete block pavement systems applying a cohesive model. The functionality of the proposed model is compared to experimental investigations of beam bending tests. The pavement is modelled as a slab on grade and parameters influencing the response such as geometry, material parameters and loading position are studied and compared to experimental results. It is found that a cohesive model is suitable for the description of the fracture behaviour of cement bound granular mixtures. Moreover, it can be shown that adequately good prediction of the structural response of composite pavements is obtained for monotonic loading without significant computational cost, making the model applicable for engineering
\end{abstract}

\footnotetext{
${ }^{*}$ Corresponding author

Email address: asch@cowi.dk (Asmus Skar)

${ }^{1}$ Industrial researcher

${ }^{2}$ Associate Professor
} 
design purpose. It is envisaged that the methodology implemented in this study can be extended and thereby contribute to the ongoing development of rational failure criteria that can replace the empirical formulas currently used in pavement engineering.

Keywords: cement bound material fracture, cohesive model, composite pavements, pavement analysis, finite element modelling, slabs on grade, aggregate interlock behaviour, slab soil interaction

\section{Introduction}

Ports- and industries require special types of pavements to resist the heavy static loads from containers. To reduce the risk of rutting and settlements over time, concrete block pavement systems are typically applied over a stiff cemented base layer, i.e., cement bound granular mixture (CBGM). The structural design of such composite pavements are based on empirical formulas which converts the response analysis into a measure of performance, commonly referred to as the Mechanistic-Empirical (M-E) method, first introduced in pavement engineering by Kerkhoven and Dormon [1].

Degradation of the cemented base in composite pavements is mainly controlled by initiation and propagation of longitudinal cracks in wheel paths. Moreover, traffic induces further degradation of aggregate interlock joints through shear movement of the cracked edges [2]. Closely spaced transverse cracks in the cemented base have also been reported in post-processing of damaged composite pavements [3, 4]. Despite the fact that cement bound granular mixtures are quasi-brittle materials, which degradation is controlled by tensile damage of slabs and shear damage of aggregate interlock joints, both highly nonlinear phenomena, elastic calculations are most commonly applied to determine the response $[5,6,7,8,9,10,11]$. The M-E method does not distinguish between crack initiation and crack propagation or elastic and inelastic work, model parameters are simply regression constants without direct physical meaning. This type of model deals with a limited number of materials in a restricted range of design options; each transfer function being restricted by its own design method, typically calibrated for highway traffic and specific local materials- and climatic conditions. Moreover, experimental studies [12] show that such empirically based model yields unrealistic results considering loading regime- or configuration different from typical truck wheel loads, e.g. ultimate loading condition. 
In the present study a simple framework for engineering application is sought; creating a rational link between laboratory, design and field applications. For the monotonic load case, considered here, the mechanism of cracks is imagined to occur in a similar fashion to yield line mechanisms considering Mode I (opening mode) fracture in the form of a straight separation band where the location is known in advance. In this aspect, the concept of the fictitious crack model [13] stand out as particular attractive; as the model is straightforward in implementation and requires only few model parameters, which can be defined from standardized laboratory tests.

Production of cement bound mixtures from high quality crushed aggregates results in high stiffness and strength properties, i.e., 1/3 of those for normal plain concrete. Not only will such materials exhibit softening behaviour in tension, after the onset of cracking, but also on structural level the composite pavements will often exhibit softening, or so-called snap-back type of load-displacement response, due to the relatively low stiffness of supporting layers. This type of localized fracture behaviour can be described numerically with different classes of constitutive models, e.g., those proposed by Jirasek [14] as; (i) strong discontinuity models, (ii) weak discontinuity models, and (iii) continuum models. The first model a crack as a geometrical discontinuity, whereas the latter two approaches imagine a cracked solid to be a continuum.

The discontinuity models, e.g. the fictitious crack model, embedded elements with strong discontinuities [15] and the extended finite elements [16], incorporates jumps in displacements across a discontinuity surface corresponding to the crack. Models with localization bands bounded by weak discontinuities can be considered as simple regularizations of models with strong discontinuities, e.g. the smeared crack model [17]. Instead of splitting the constitutive law into elastic and inelastic parts, one could use a law that directly links the stress to the total strain, as is the case for continuum models. Subsequently several models have been developed to describe the complicated fracture process in quasi-brittle materials, e.g., by coupling damage and plasticity [18, 19, 20].

Application of modern fracture mechanics to the field of pavement engineering began in the late 1960s and early 1970s, studying mainly asphalt concrete mixtures, adopting the principles of linear elastic fracture mechanics $[21,22,23,24,25]$. Subsequently, efforts to obtain a better understanding of fracture in asphalt concrete materials primarily followed an experimental approach [26, 27, 28, 29]. Jenq and Perng [30] developed a cohesive zone model 
based on the principles of the fictitious crack model for asphalt mixtures and used this model to simulate low-temperature fracture of asphalt overlay on old concrete pavement structures [31] followed by extensive applicationand development of cohesive zone models for simulating fracture in asphalt concrete mixtures [32, 33, 34, 35, 36, 37, 38, 39].

Cohesive zone models and the principles of the fictitious crack model has also been extended to more practical problems for concrete pavement structures, following an extensive review of fracture mechanics applications in pavement engineering [40]. At first, a standalone computer program was coded and applied to simply supported beams [41]. Subsequently, nonlinear spring elements were adopted in commercial software for concrete beams and slabs on grade subjected to mechanical loads [42]. Roesler et al. [43] created user elements based on the fictitious crack model, and implemented them locally in commercial software to simulate crack propagation in concrete beam specimens and in fibre reinforced concrete materials [44, 45]. Although these elements were two-dimensional, responses obtained were compared with experimental measurements and adequately good agreement was reported. Subsequently several independent investigations of crack propagation in beams and slabs on grade subjected to mechanical loads was carried out, with some very encouraging results [46, 47, 48, 49]. Gaedicke and Roesler [46] found that the linear softening model applied to slabs was able to reasonably predict the flexural load capacity of the experimental slabs while significantly reducing the computation time. Aure and Ioannides [48] found, that for slabs on grade structures, the type of softening curve, cohesive zone width and mesh does not influence the response significantly.

This paper presents a numerical study of a three-layered composite pavement applying a simplified cohesive model in ABAQUS [50], including also the effects from aggregate interlock behaviour. Idealization is applied, modelling the pavement as a slab on grade structure, neglecting the effect from the concrete block surface, resulting in computationally fast finite element (FE) models suitable for engineering applications. Numerical analysis of experimental results are presented, giving new valuable information on the behaviour of composite pavements which cannot be captured by the M-E method. Parameters influencing the response such as geometry, material parameters and loading position is then studied creating a solid basis for further application of cohesive models in analysis composite pavement systems. 


\section{Methodology}

\subsection{Model idealizations}

Analysis of a three-layered composite pavement structure is considered; concrete block pavers (CBP), cement bound granular mixture (CBGM) and subgrade soil. For the fracture process, built-in traction separation based cohesive contact surfaces are inserted along the anticipated fracture plane in the cemented base layer (slab) in the orthogonal directions as per Meda et. al. [51]. This is deemed a reasonable model at the edge- and interior of the cemented base layer, since the fracture plane is anticipated in the direction of the maximum stress.

The response of the composite concrete block pavement structure is mainly controlled by the cemented base layer and the subgrade soil. The properties and thickness of the concrete block pavers does hardly influence the overall response and bearing capacity of the pavement structure [52], since the loading from container castings produce a close to rigid body movement of the stiff concrete block pavers over the soft layer of bedding sand, which is unable to absorb any significant bending moments [53].

Thus, for the present study the response from concrete block pavers is simulated using a simplified approach, placing unit displacements over an approximated area, i.e., the area of blocks in contact with the container casting. Four single slabs on grade models is developed for evaluation of interior (full- and simplified model, applying symmetry conditions), edge and corner loading, assuming that the slabs are intact before monotonically loaded. Square slabs of $2.5 \times 2.5 \mathrm{~m}^{2}$ to $4.5 \times 4.5 \mathrm{~m}^{2}$, dimensions commonly applied in ports- and industrial pavements, is considered.

In this study, commercial general purpose FE program ABAQUS/Standard ${ }^{\circledR}$, version 6.13-1 is employed in the analysis of beams- and slab on grade structures, whose geometry and material properties are shown in Table 1 and Table 2. Foundation material properties are given in in Table 3.

\subsection{Constitutive laws and materials}

\subsubsection{Cohesive crack and cemented material behaviour}

In the present study cement bound granular mixtures with relatively high strength, i.e., a $C_{8 / 10}$-material ([54]), commonly applied in port- and industry composite pavements, is considered. Such materials have similar characteristics as normal plain concrete, however, whereas concrete are dense mixtures, where aggregates are completely bonded by the cement paste, as shown in 
Figure 1 (a). Cement bound granular mixtures are less dense and aggregates are bonded by weaker cement links, as shown in Figure 1 (b), resulting in somewhat lower strength and more brittle behaviour.

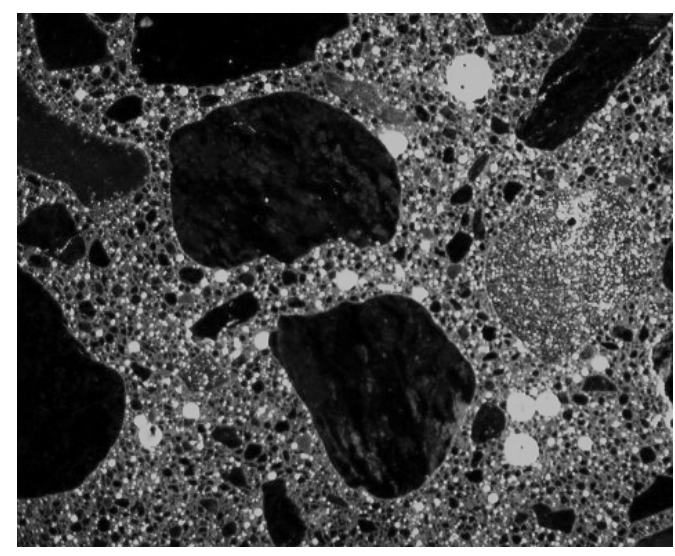

(a)

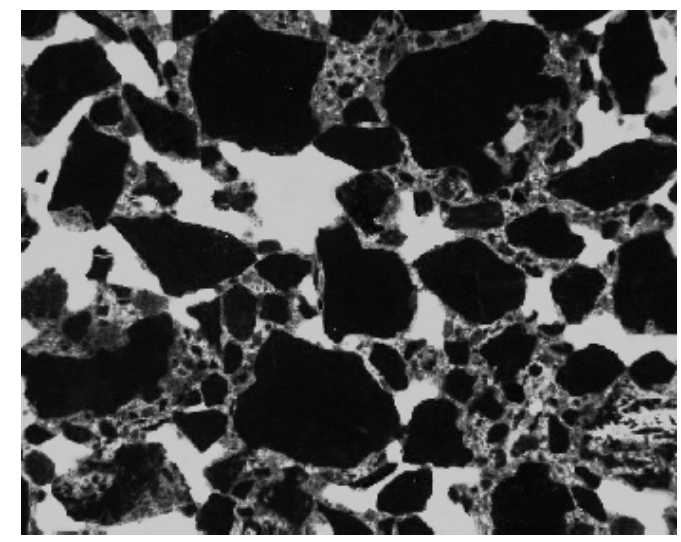

(b)

Figure 1: Thin section of normal concrete (a) and cement bound granular mixture (b), showing how aggregates in the cement bound granular mixture is connected by cement links surrounded by more porous areas with loosely packed sand held by relatively little paste.

Overview of geometry and cement bound granular material mixture properties for beams- and slabs used in the numerical studies are shown in Table 1. Grading curves for materials investigated in numerical analysis of experimental results in section 3.1 and 3.2 are shown in Figure 2. 


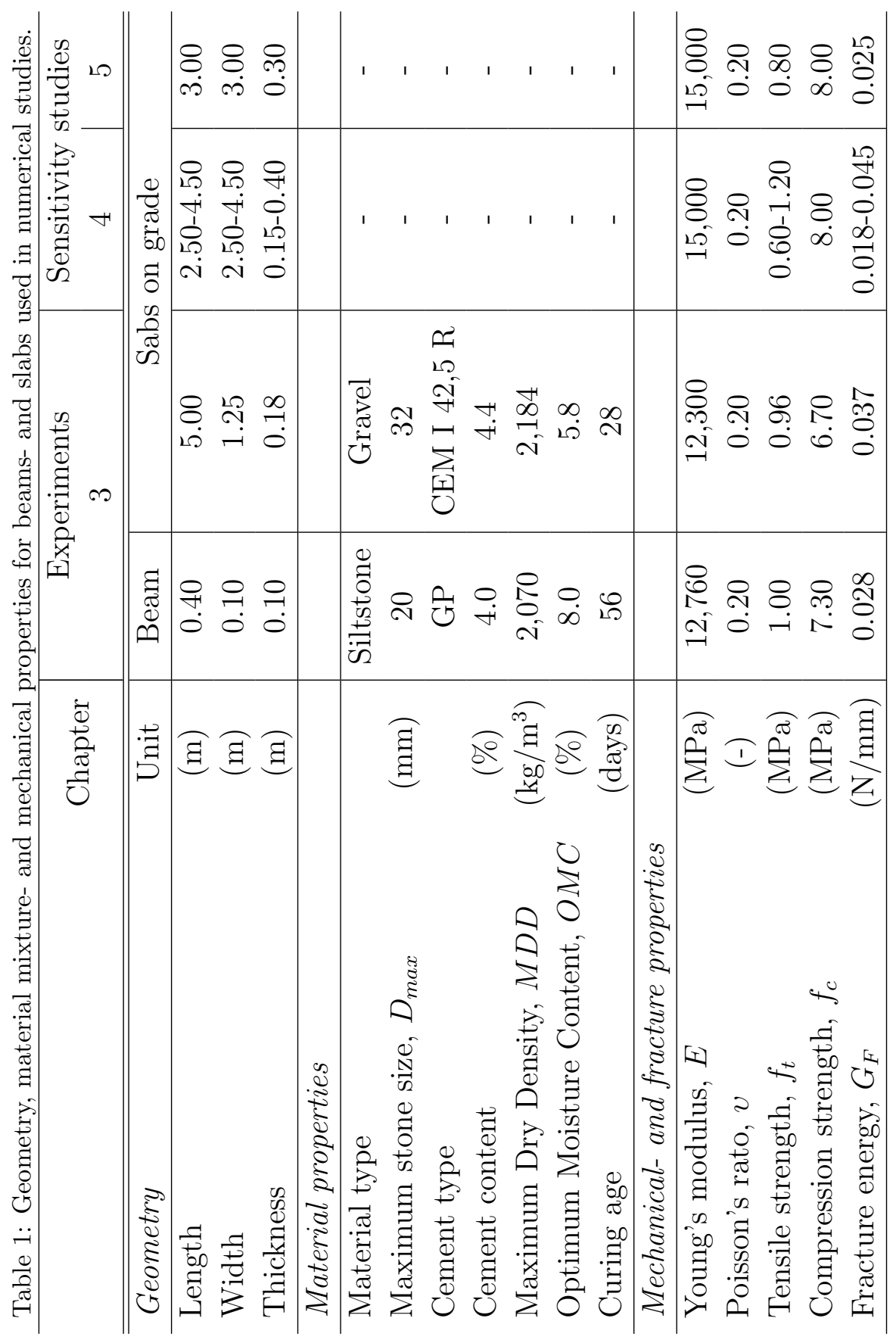




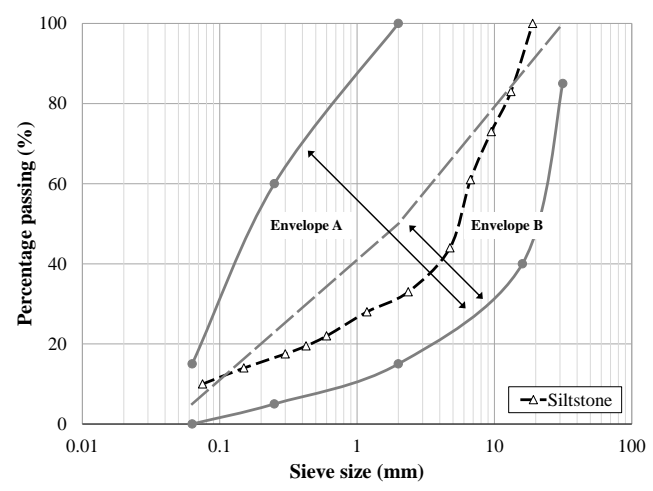

(a)

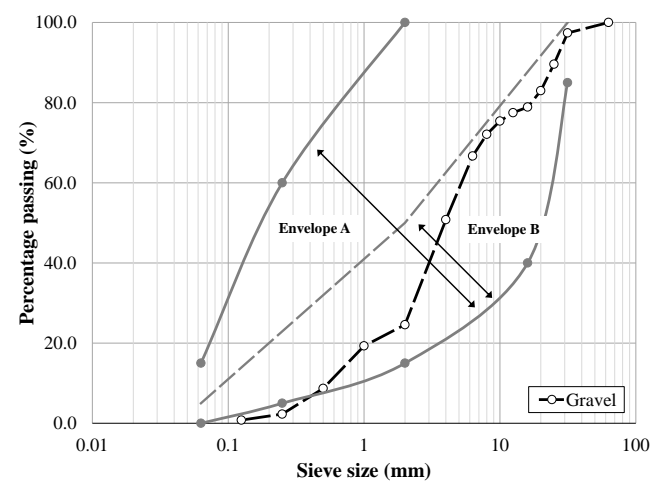

(b)

Figure 2: Grading curves for high quality (envelope 'B') CBGM materials according to [54] (grey) compared to CBGM materials used in experiments of (a) 4-point bending beamand (b) slabs on grade tests in section 3.1 and 3.2 , respectivelly.

Liu and Wang [55] applied a cohesive zone model to investigate Mode I crack propagation of cement stabilized crushed stone in the indirect tension test (IDT) following a micro-mechanical approach using embedded elements. Heymsfield et. al. [56] developed a damage model for stabilized soil layers subjected to cyclic aircraft loading. Zhong et. al. [57] developed a unified permanent deformation model to simulate the permanent deformation behaviour of cement bound granular materials in flexible pavements. However, the literature contains little information on the fracture behaviour of cemented base materials with high strength properties for application in realistic composite pavement systems. 


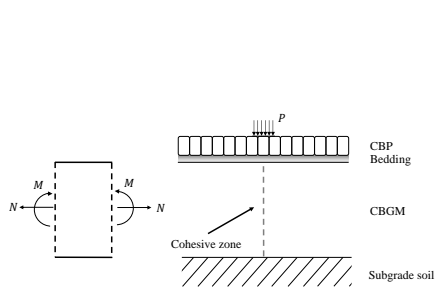

(a)
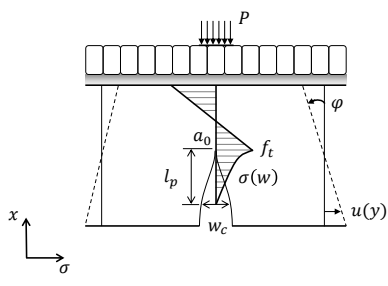

(b)

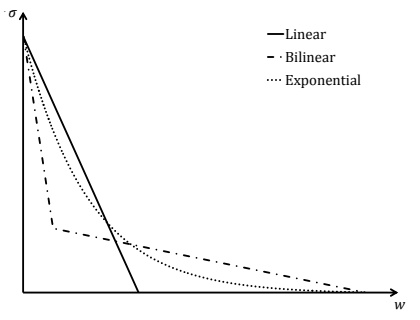

(c)

Figure 3: Sketch of pavement structure (a) the fictitious crack model (b), where $a_{0}$ is the crack tip, $l_{p}$ is the fracture process zone (FPZ), $f_{t}$ is the tensile strength, $w_{c}$, is the stress-free crack opening and $\sigma(w)$ the cohesive softening law and typical softening curves for concrete (c).

In lack of experimental data and based on the findings of other independent researchers, e.g., Gaedicke and Roesler [46] and Aure and Ioannides [48], the fictitious crack model with a simple linear traction-separation law (softening curve), as shown in Figure 3 (c), is chosen for the present study. Moreover, the fracture energy applied in the present study is predicted based on the approach suggested by Hilsdorf and Brameshuber [58], assuming that code standards for normal concrete also apply to cement bound granular mixtures. 


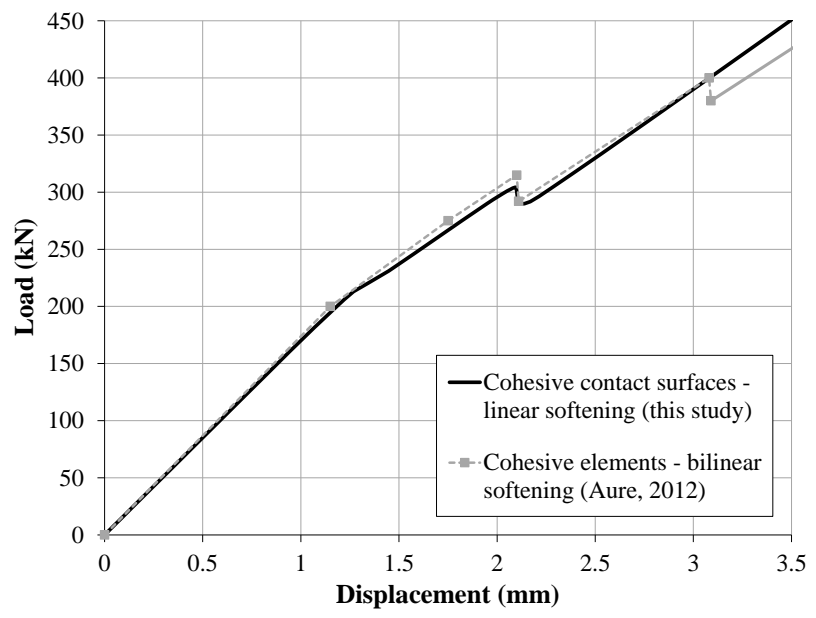

Figure 4: Comparison of load-displacement curves for interior loading of a rectangular concrete slab on grade $\left(3 \times 6 \times 0.15 \mathrm{~m}^{3}\right)$, applying different modelling techniques in ABAQUS: cohesive contact surfaces applying a linear softening law and cohesive zone element size (h/l) of $8 \times 15 \mathrm{~mm}^{2}$ to $8 \times 65 \mathrm{~mm}^{2}$ (this study) versus cohesive elements using bilinear softening law and a relatively fine mesh of $3.5 \times 3.5 \mathrm{~mm}^{2}$ for the cohesive zone (Aure, 2012 $[48])$.

The cohesive contact model in ABAQUS is selected to save computational time; enabling the use of symmetry conditions and application of a coarser mesh for the cohesive zone. Moreover, as shown in Figure 4, the cohesive contact model in ABAQUS is found to adequately describe the load-displacement response of slabs on grade reported by other independent researchers.

\subsubsection{Aggregate interlock behaviour}

The mechanics of aggregate interlock between slabs, shown in Figure 5, is a complex phenomenon that depends on several parameters, including aggregate size and distribution, compressive strength, friction between the aggregate particle and the cement paste, crack opening, and crack interface sliding. 


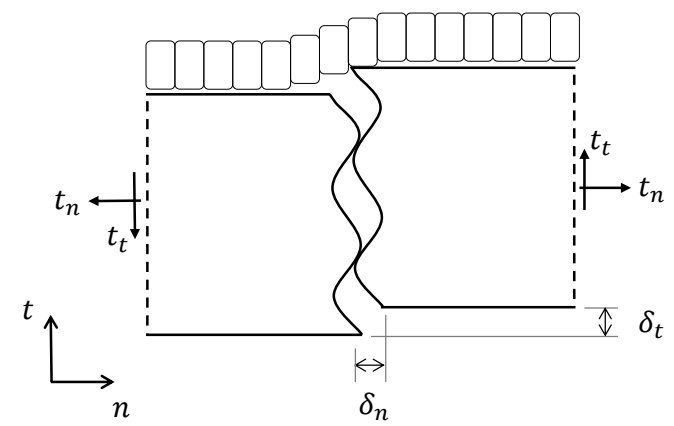

Figure 5: Sketch of the rough crack model [59] within the composite pavement system.

According to Bazant and Gambarova [59], the normal and shear stresses at a cracked concrete interface, in a two-dimensional plane, are functions of the normal and shear displacements of the interface, as follows:

$$
\begin{aligned}
& t_{n}=f_{n}\left(\delta_{n}, \delta_{t}\right) \\
& t_{t}=f_{t}\left(\delta_{n}, \delta_{t}\right)
\end{aligned}
$$

where $t_{n}$ is the normal stress, $t_{t}$ is the tangential shear stress, $\delta_{n}$ and $\delta_{t}$ are the normal and shear displacements respectively, and $f_{n}$ and $f_{t}$ are functions to be described. Differentiation of equation $1 \mathrm{a}$ and $1 \mathrm{~b}$ results in:

$$
\left\{\begin{array}{l}
d t_{n} \\
d t_{t}
\end{array}\right\}=\left[\begin{array}{ll}
\frac{\partial f_{n}}{\partial \delta_{n}} & \frac{\partial f_{n}}{\partial \delta_{t}} \\
\frac{\partial f_{t}}{\partial \delta_{n}} & \frac{\partial f_{t}}{\partial \delta_{t}}
\end{array}\right]\left\{\begin{array}{l}
d \delta_{n} \\
d \delta_{t}
\end{array}\right\}=\left[\begin{array}{ll}
K_{n n} & K_{n t} \\
K_{t n} & K_{t t}
\end{array}\right]\left\{\begin{array}{l}
d \delta_{n} \\
d \delta_{t}
\end{array}\right\}
$$

where $K_{n n}=\partial f_{n} / \partial \delta_{n}, K_{n t}=\partial f_{n} / \partial \delta_{t}, K_{t n}=\partial f_{t} / \partial \delta_{n}, K_{t t}=\partial f_{t} / \partial \delta_{t}$, are crack stiffness coefficients that can be determined once the functions $f_{n}$ and $f_{t}$ are established. If the variation of functions $f_{n}$ and $f_{t}$ is nonlinear with respect to $\delta_{n}$ and $\delta_{t}$, the crack stiffness coefficients may be sensitive to stress level of the cracked interface, and therefore, will change as the load is applied. This behaviour is identified as nonlinear aggregate interlock mechanism. Several constitutive models for nonlinear aggregate interlock behaviour (crack dilatancy) have been proposed in the literature, e.g.: the 
rough crack model [59, 60], the aggregate interlock relation [61], the twophase model [62] and the contact density model [63].

In lack of adequate experimental data the modified rough crack model [60], incorporating both influence of aggregate size and compression strength, is used as basis to determine the stiffness coefficients of springs as seen in Figure 6. Linear normal stiffness with no dependence on initial crack width is assumed. Material parameters for aggregate interlock behaviour used in numerical studies are shown in Table 2.

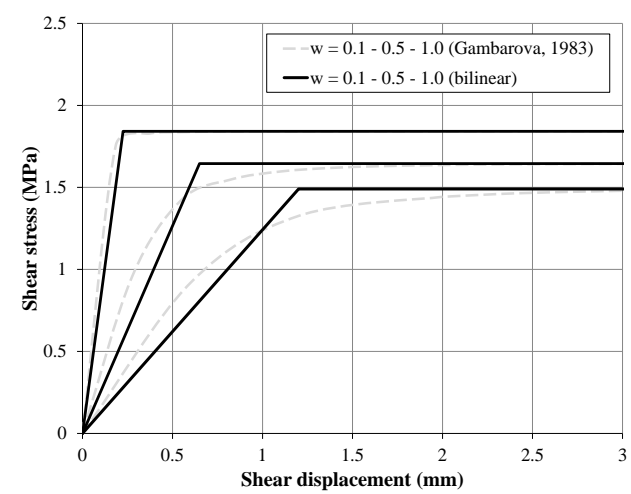

(a)

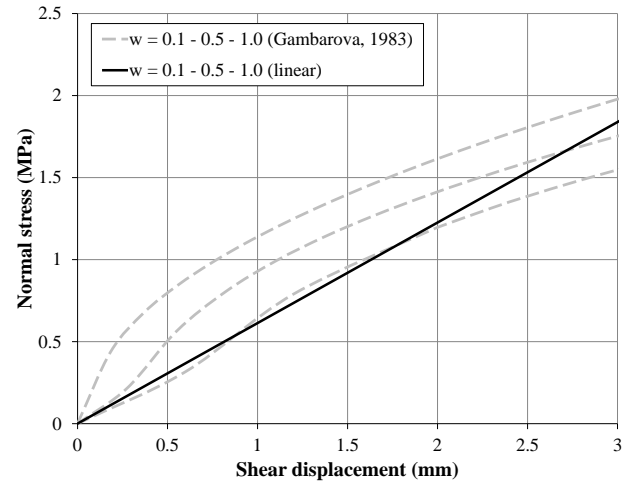

(b)

Figure 6: Linear idealization of the modified rough crack model (Gambarova, 1983 [60])

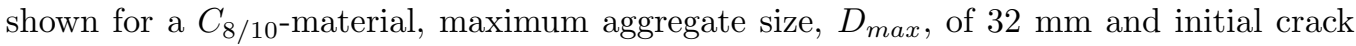
width, $w$, of $0.1,0.5$ and $1.0 \mathrm{~mm}$.

Table 2: Aggregate interlock behaviour used in numerical studies.

\begin{tabular}{lc|c|c|c|c}
\hline & \multirow{2}{*}{ Chapter } & \multicolumn{2}{|c|}{ Experiments } & \multicolumn{2}{|c}{ Sensitivity studies } \\
& & \multicolumn{2}{|c}{3} & 4 & 5 \\
\hline \hline Aggregate interlock & Unit & Beam & \multicolumn{3}{|c}{ Sabs on grade } \\
\hline Initial crack width, $w$ & $(\mathrm{~mm})$ & - & 2.00 & - & $0.40-2.00$ \\
Load Transfer Efficiency, $L T E_{\delta}$ & $(\%)$ & - & 50 & - & $50-90$ \\
Normal stiffness, $K_{n n}$ & $(\mathrm{MPa} / \mathrm{mm})$ & - & 0.45 & - & 0.45 \\
Initial tangential stiffness, $K_{t t}$ & $(\mathrm{MPa} / \mathrm{mm})$ & - & 0.65 & - & $0.65-3.00$ \\
Critical shear displacement $(\mathrm{slip})$ & $(\mathrm{mm})$ & - & 2.00 & - & $0.58-2.00$ \\
\hline
\end{tabular}




\subsubsection{Subgrade material behaviour}

In the present study the subgrade has been idealized as linear elastic using independent springs or a so-called Winkler's foundation model [64]. However, to exemplify the deficiencies of this model and to evaluate full bearing capacity of the structure, elastic solid continuum elements, including a Mohr-Coulomb yield criterion [50], is applied in the numerical analysis of experiments in section 3.2. Overview of subgrade material properties used in the the numerical studies are shown in Table 3. Grading curve for the subgrade material investigated in numerical analysis of experimental results in section 3.2 is shown in Figure 7. 


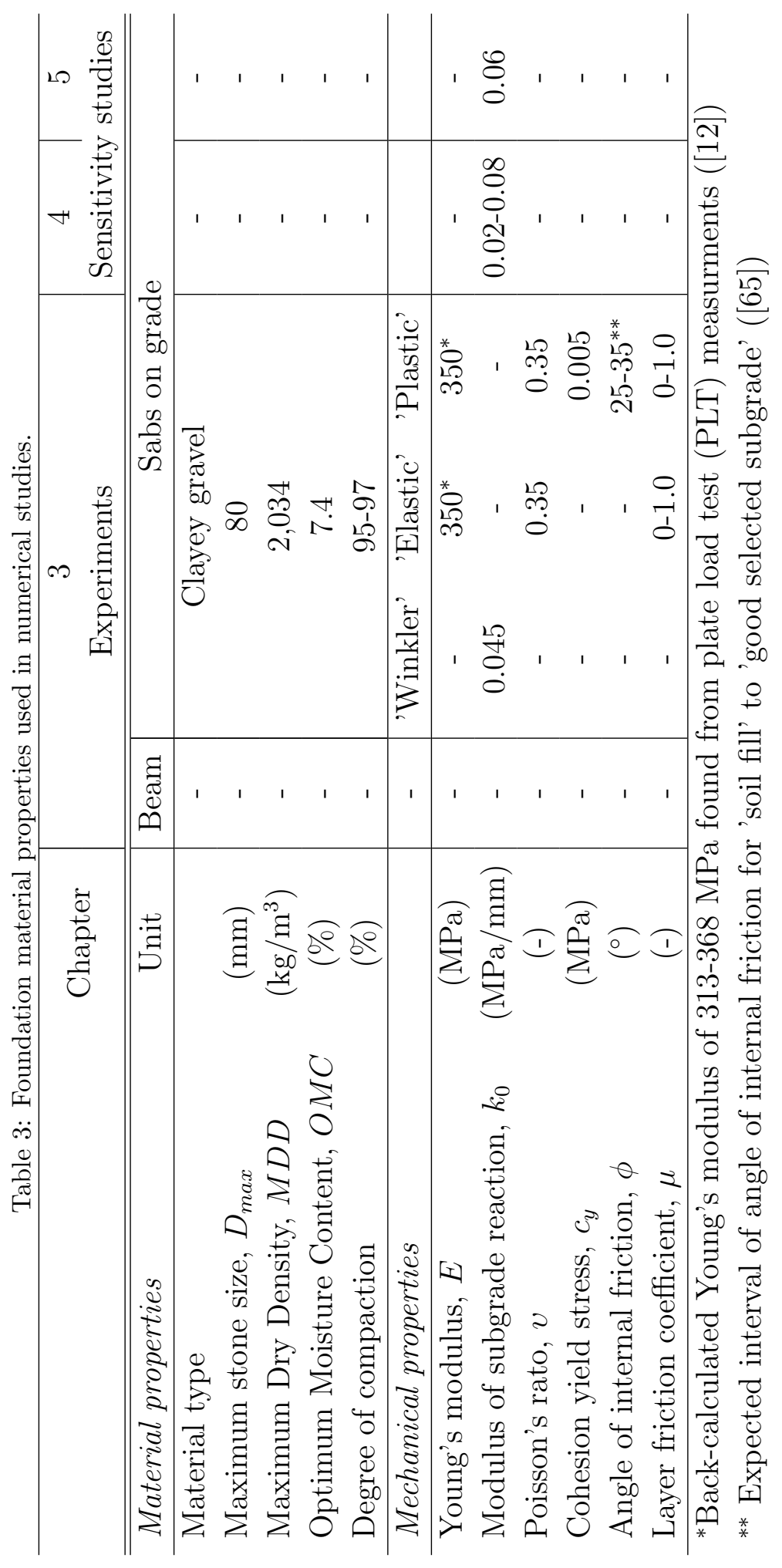




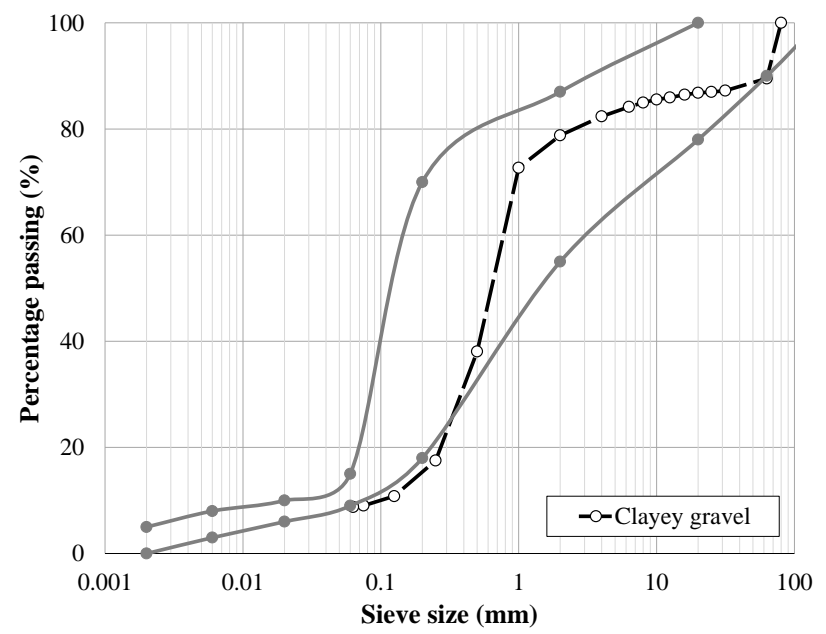

Figure 7: Grading curve for clayey gravel material ('SP-SC') according to [66] (grey) compared to clayey gravel material used in experiments of slabs on grade tests in section 3.2 .

\subsection{Solution technique}

In materials that exhibit snap-back type of load-displacement curves, arclength based solvers are often recommended. Accordingly ABAQUS implements the so-called modified Riks algorithm ([67]) used in the present study. Based on preliminary convergence and sensitivity studies solution technique and standard model parameters selected for the present study can be seen in Table 4.

Table 4: Solution technique and standard model parameters applied in the present study.

\begin{tabular}{lc|lc}
\hline \multicolumn{2}{c|}{ Solver } & \multicolumn{2}{c}{ Model parameters } \\
\hline \hline Technique & arc-length & Cohesive zone width, $T_{0}$ & $0.01 \mathrm{~mm}$ \\
Initial incr. & 0.006 & Viscous damping factor, $\mu$ & $1 \times 10^{-5}$ \\
Max. incr. size & 0.03 & Bulk elements (elastic) & CPE4 (2-D) / C3D8 (3-D) \\
Min. incr. size & $1 \times 10^{-9}$ & Interface elements & SPRING1/el. foundation \\
\hline
\end{tabular}




\section{Comparison with experimental results}

\subsection{Numerical analysis of four point bending tests with cement bound gran- ular mixture}

Numerical analysis of four-point bending (FPB) beam tests is carried out to verify the functionality of the cohesive contact model to simulate the fracture behaviour of cement bound granular mixture with crushed quartzite siltstone aggregates. Five CBGM-beams was cut from field slabs and tested under monotonic load, with a distance of $0.10 \mathrm{~m}$ between load points, in a comprehensive study of CBGM-materials conducted by Austroads [68]. Geometry and material properties is shown in Table 1.

The beam is modelled with 2-D plain stress elements (CPE4) in ABAQUS. A total of 840 elements are used to represent the elastic material, separated by pre-determined contact surfaces, representing the cohesive zone $(5 \mathrm{~mm}$ size elements), in the vertical plane at the mid-beam position.

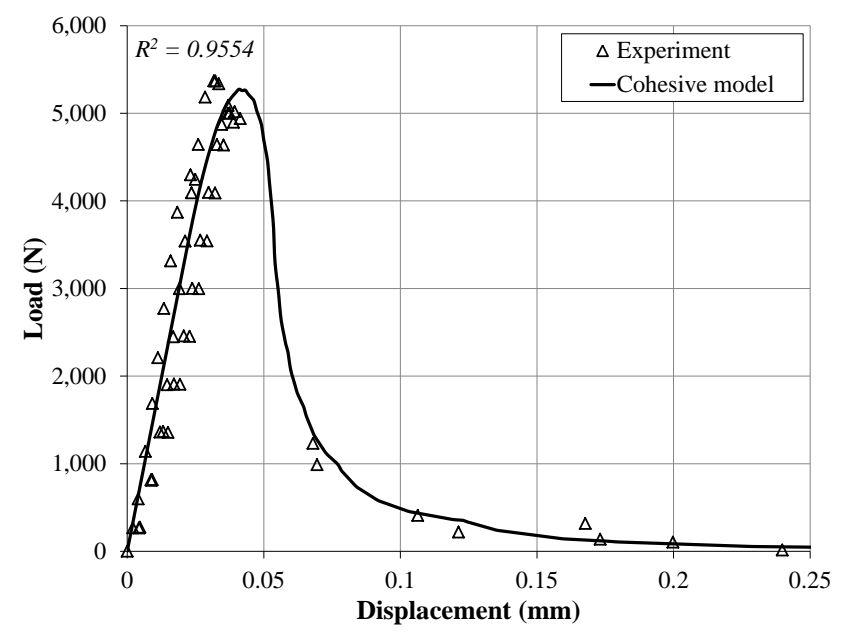

Figure 8: Comparison between experiments, carried out by Austroads [68] and numerical results for CBGM beams.

From the comparison between experimental and numerical results, shown in Figure 8, it can be observed that good agreement is obtained applying the cohesive model for simulation of the load-displacement response of the four-point bending beams. Relatively few data-points were obtained on the post-peak failure curve as no horizontal clip-gage control was applied during 
testing. The results show that a linear softening law is suitable to the description of fracture in cement bound granular mixtures. It is also found that the fracture energy of the cement bound granular mixture can be predicted without further calibration, based on simple scaling with regard to compressive strength, e.g., $G_{F, C B G M}=f_{c, C B G M} / f_{c, P C C} \times G_{F, P C C}$, or code standards for concrete materials.

\subsection{Numerical analysis of large scale slab on grade structure}

Numerical analysis of cement bound granular mixture slabs, shown in Figure 9, separated by aggregate interlock-or construction joints, on subgrade soil of $1.0 \mathrm{~m}$ clayey gravel material, is conducted in order to validate the methodology implemented, modelling the composite pavement as a slab on grade structure. The pavement was constructed on a concrete floor supported by a steel-or concrete wall in the indoor test facility STEND in Poland. The data was collected during the European Commission thematic network project ECO-serve $[12,69,70]$ and was partly initiated in the attempt to evaluate the before mentioned M-E models.

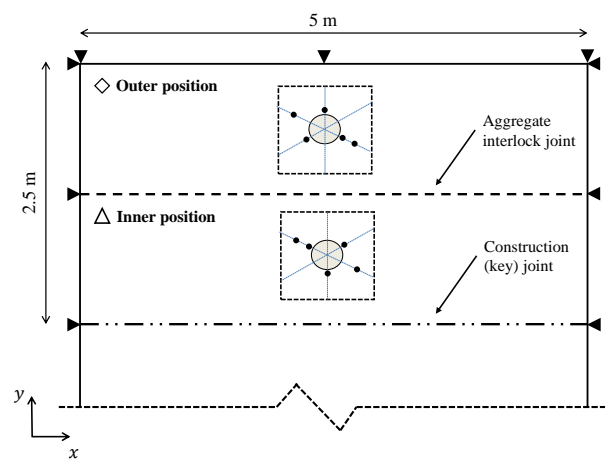

(a)

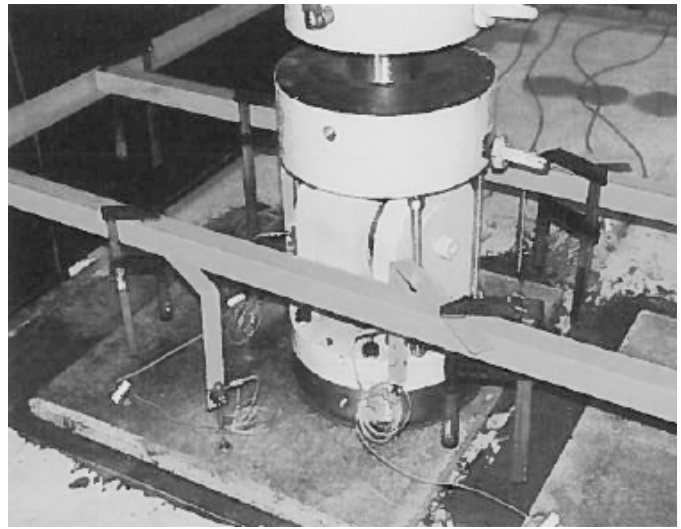

(b)

Figure 9: Layout of slabs, showing outer- and inner loading position, supports ( $\mathrm{x}$ axis:concrete wall, y-axis:steel wall) and the placing of displacement sensors (a) and picture of test set-up (b), showing the load configuration and the displacement sensors placed on top of a $35 \mathrm{~mm}$ thin asphalt plate.

The success in the application of M-E models was modest at best, as no or little damage was recorded during each load cycle as shown in Figure 10 (a). To reduce the test time, the load was increased from typical equivalent 
standard axle load (ESAL) of 50-60 kN (per wheel) to $150 \mathrm{kN}$. However, to record damage development, the load was finally increased to $250 \mathrm{kN}$, which caused excessive cracking in the cement bound granular mixture and local yielding of the subgrade soil foundation below the plate load, correlating badly with the M-E models calibrated for highway pavement design. The experimental load displacement curves for the the two load series are shown in Figure 10 (c) and (d) for displacements measured at a distance of 235 and $450 \mathrm{~mm}$ from the loaded centre, respectively.

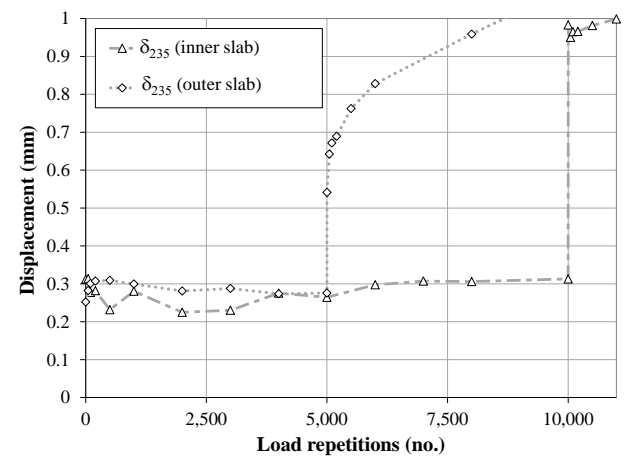

(a)

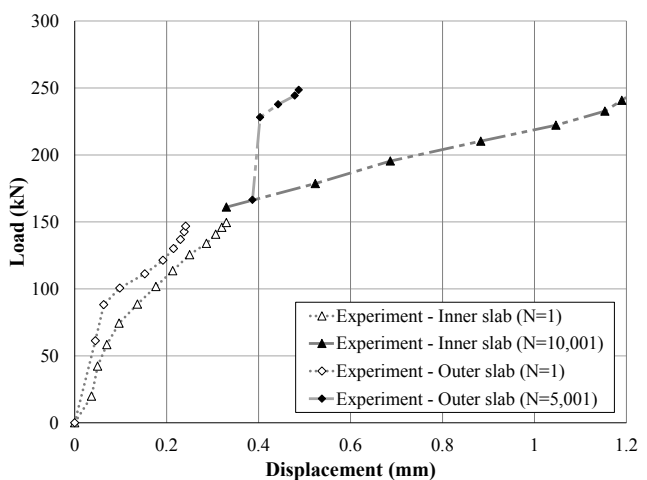

(c)
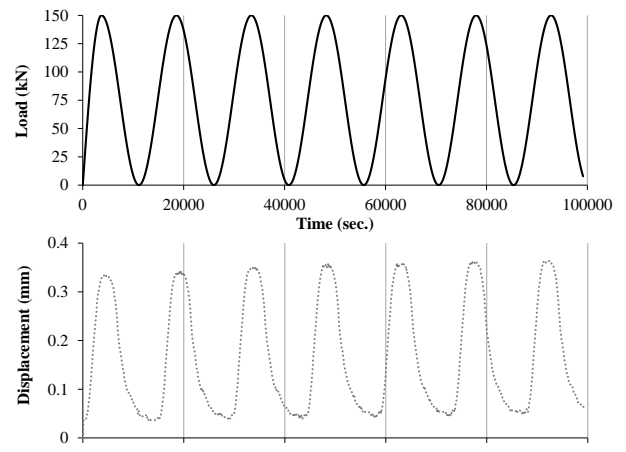

(b)

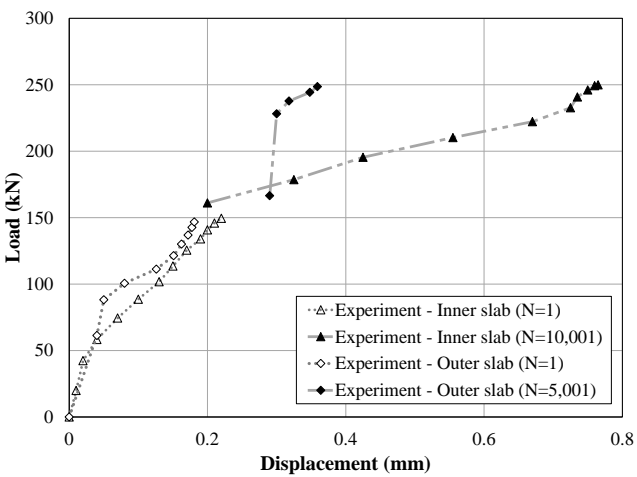

(d)

Figure 10: Presentation of experimental data: Average peak-loads and peak-load displacements measured during experiments at a distance of $235 \mathrm{~mm}$ from the load centre (a), example of typical sinusoidal load applied to the pavement (b); first seven load cycles for the inner slab position at a distance of $235 \mathrm{~mm}$ from the load centre and experimental load-displacement curves at a distance of $235 \mathrm{~mm}$ (c) and $450 \mathrm{~mm}$ (d) from load centre. 
From Figure 10 it can be observed that the load-displacement curves extracted from the two load series, for the inner slab ( $\mathrm{N}=1$ and $\mathrm{N}=10,001)$ and the outer slab ( $\mathrm{N}=1$ and $\mathrm{N}=5,001)$, follow each other closely up to the load level of app. $150 \mathrm{kN}$. Then, the inner slab shows a pronounced drop in stiffness. Similar drop in stiffness is also indicated for the outer slab, but at a higher load level of app. $225 \mathrm{kN}$. The most likely explanation for this difference in structural response, can be found in the natural variation in subgrade soil properties and it's shear strength, which is highly influenced by the angle of internal friction, and the different number of load cycles between load steps which can have caused a different damage state of the subgrade soil, slabs and aggregate interlock joints.

The load, asphalt surface and slab geometry, shown in Figure 11 (a), is modelled with solid 3-D elements (C3D8 and C3D6) in ABAQUS. A total of 51,155 elements are used to represent the elastic material, shown in Figure 11 (b), separated by pre-determined cohesive contact surfaces, representing the cohesive zone (average $10 \mathrm{~mm}$ size elements), in the vertical plane in orthogonal directions. The average strength properties of the cemented material were determined from specimens extracted from slabs, shown in Table 1. The cohesive model is evaluated applying three different subgrade models with mechanical material properties as shown in Table 3.

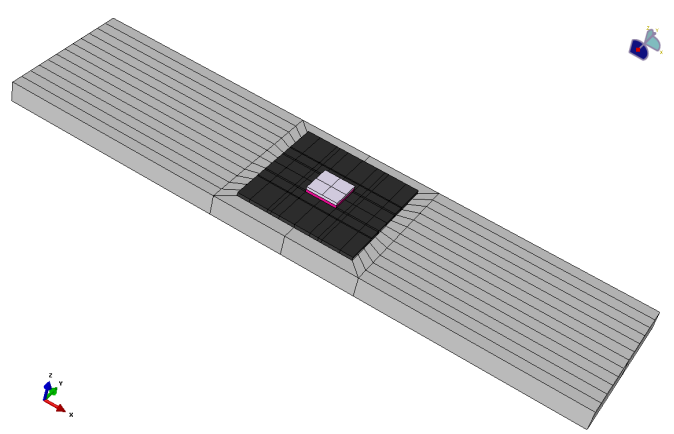

(a)

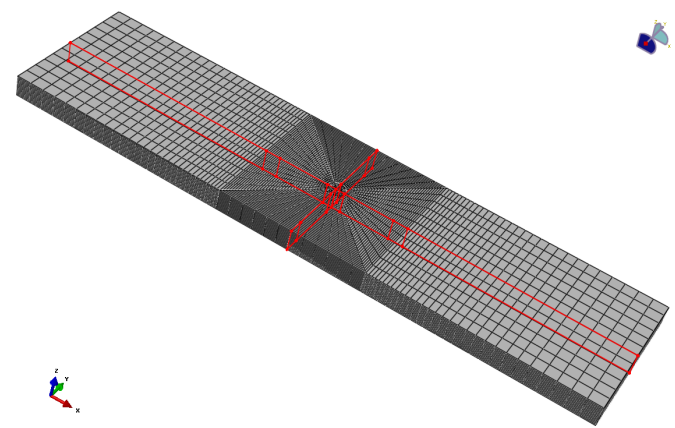

(b)

Figure 11: Sketch of FE model (a), showing the load- and rubber plate, asphalt surface, and CBGM slab, and mesh and pre-determined cohesive zone in the slab orthogonal planes (b).

From comparison between numerical and experimental load-displacement curves at a distance of $235 \mathrm{~mm}$ and $450 \mathrm{~mm}$ from the load centre, shown in 
Figure 12 (a) and (b), it can be observed that relatively good agreement is obtained between experimental and numerical results up to the peak-load for all three models. The peak-load is app. 157, 133 and $162 \mathrm{kN}$ for the 'Elastic', 'Winkler' and 'Plastic' model, respectively. The experimental result shows a pronounced post-peak decrease in stiffness at a load level of app. $150 \mathrm{kN}$, probably due to local plastic yielding of the subgrade soil. This behaviour can only be captured by the 'Plastic' model. Moreover, it is found that modelling the subgrade soil with elastic solid continuum elements result in a more realistic prediction of the peak-load compared to the 'Winkler' model as this model essentially suffers from a complete lack of continuity in the supporting medium, neglecting the shear stiffness of the subgrade soil. The influence of subgrade soil model type on local crack behaviour can be seen in Figure 13.

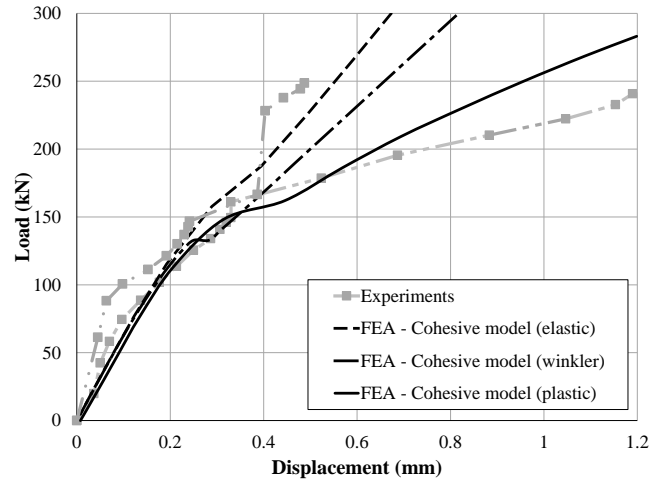

(a)

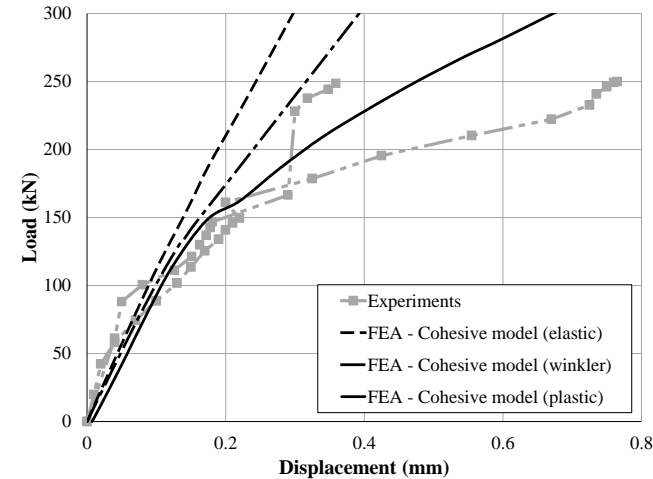

(b)

Figure 12: Comparison between experiment and numerical analysis showing the loaddisplacement curves obtained at a distance of $235 \mathrm{~mm}$ (a) and $450 \mathrm{~mm}$ (b) from load centre for the three selected subgrade models 'Winkler', 'Elastic' and 'Plastic' using a angle of internal friction of $30^{\circ}$ for the latter model.

From the load versus crack mouth opening displacement (CMOD) curve in Figure 13, it can be observed that cracks in both directions are initiated at load point 1, damage of the cohesive crack then progress toward the edges of the slab. At load level point 2, nodes at the bottom of the slab in length direction (shortest direction) have exceeded the final (zero traction) displacement. The cohesive zone then progress upwards until the 'snap' at load level point 3, resulting in the kink on the load-displacement curve in Figure 13 (a) 
and (b), whereas the crack in the width remains stable in the width direction as shown in Figure 13 (b) and (c). Unloading on the load-displacement curve is prevented by the high stiffness of the subgrade soil and the geometry of the slab. At load level point 4, all nodes in the length direction have exceeded the final displacement, as shown in 13 (c).

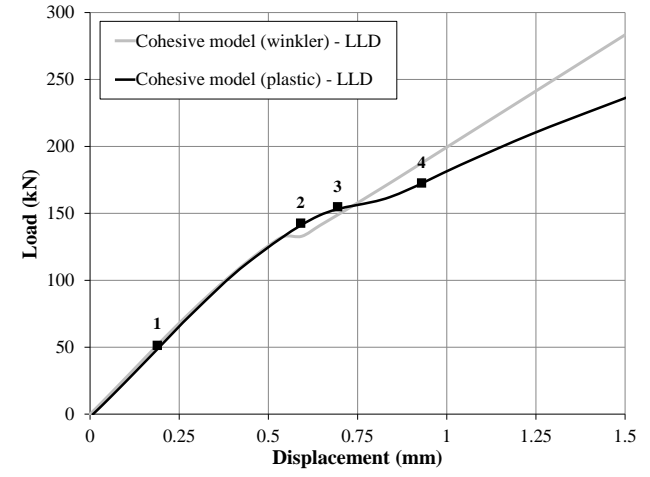

(a)

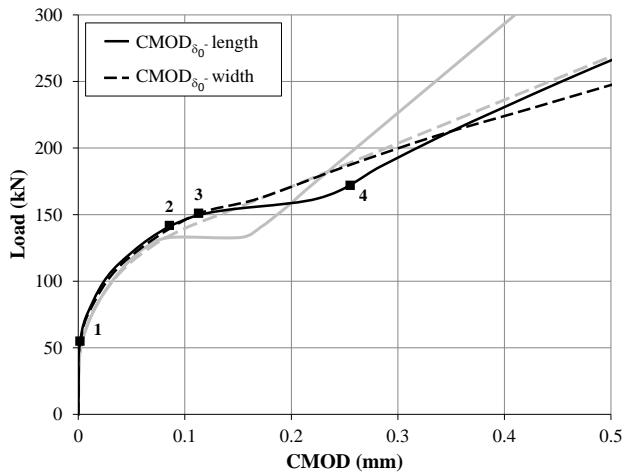

(b)

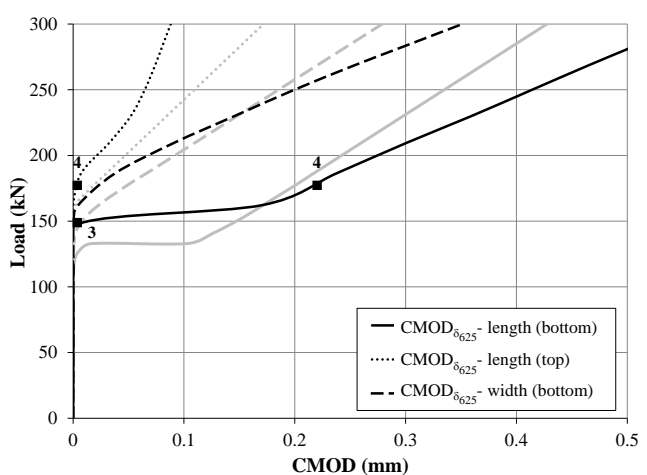

(c)

Figure 13: Presentation of numerical results for the 'Winkler' (grey) and 'Plastic' (black) subgrade model: load line displacement (LLD) (a), load-CMOD curve for cohesive crack at the bottom of the slab under the load centre (b), and load-CMOD curve for the cohesive crack at the bottom and the top of the slab $625 \mathrm{~mm}$ from load centre in the length direction and at the bottom in the width direction.

The numerical results shown in Figure 13 can explain some of the observations made during the experimental investigations which couldn't be 
described by the M-E models. The most obvious observation is that the crack along the length (shortest direction) has fully propagated at the applied load of $150 \mathrm{kN}$ (load level point 3), explaining why no damage was recorded during experiments with repeated loads at this load level. Then, the response is controlled by further crack propagation along the width and the subgrade soil behaviour. Moreover, it is observed that cracking is initiated at load level 1 of $50 \mathrm{kN}$, the same load magnitude as a equivalent standard axle loads. 


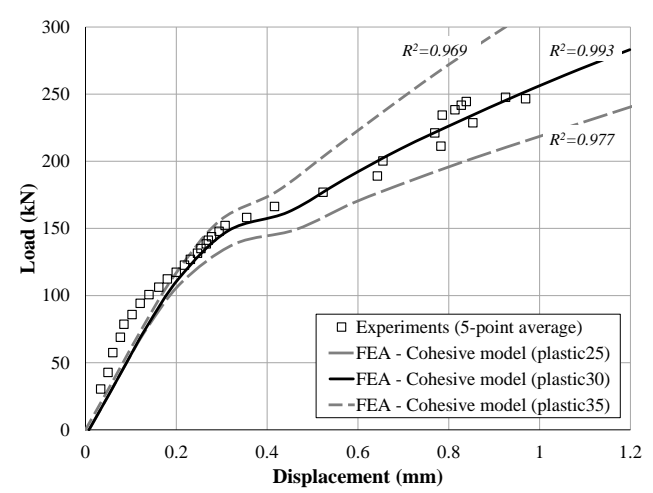

(a)

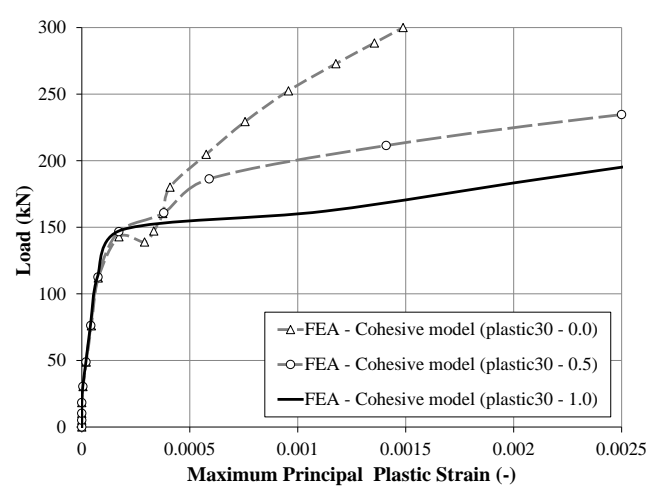

(c)

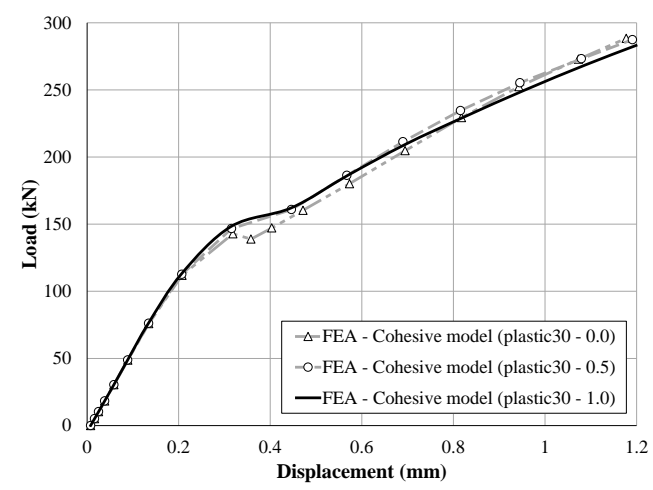

(b)

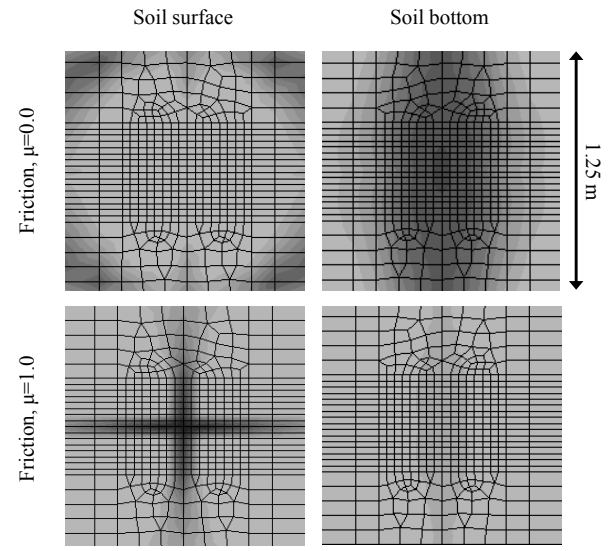

(d)

Figure 14: Comparison between averaged experimental- and numerical results for the the 'Plastic' model: (a) and (b) influence of angle of internal friction $\left(\phi=25-35^{\circ}\right)$ and friction coefficient $(\mu=0-1.0)$ between the cemented slab and subgrade soil layer on the load-displacement curves at a distance of $235 \mathrm{~mm}$ from load centre, (c) influence friction coefficient on maximum principal plastic strains and (d) plastic strain distribution in the peak-region at the top and bottom of the subgrade soil layer at the maximum load level of $250 \mathrm{kN}$.

From Figure 14 (a) it is observed that the angle of internal friction has significant influence on the load-displacement response. However, a relatively good fit between averaged experimental- and numerical results can be found for all models in the expected interval. It is also found, that the friction between layers has little influence on the overall structural response, but 
significant influence on local subgrade soil response, as shown in Figure 14 (b) and (c), respectively. Increasing friction between layers results increasing maximum plastic strains and strain localization at the subgrade soil surface below the loaded plate. Whereas no friction, gives larger distribution of strains, increasing towards the bottom of the layer as shown in Figure 14 (d).

\section{Sensitivity studies}

\subsection{Model idealizations}

To investigate the influences of geometry and important material properties on the model response a sensitivity study is carried out for interior loading of a single slab. The slab geometry is modelled with solid 3-D elements (C3D8I and C3D6) in ABAQUS. Symmetry conditions are applied, modelling one slab crack. Cohesive zones are inserted with a $45^{\circ}$ angle between the symmetry-lines and in an arch close to the centre.

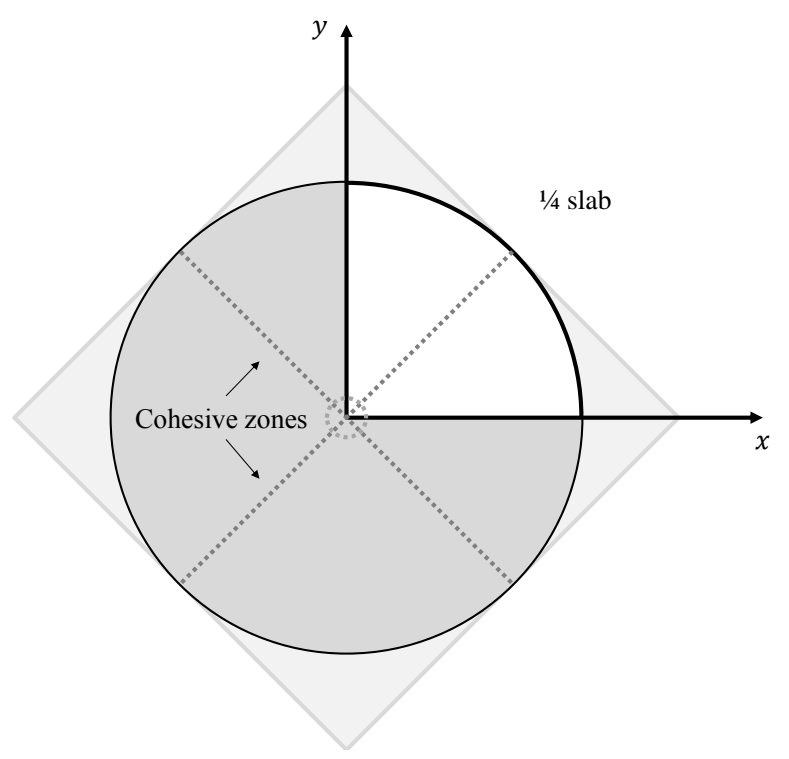

Figure 15: Sketch of model applied in the sensitivity study.

This methodology result in somewhat lower ultimate load bearing capacity of the structure, as a circular disc is considered, with an reduction in area of $20 \%$ compared to the $1 / 4$ slab. However, it is found from preliminary 
analysis that the structure sketched in Figure 15 adequately predicts the responses of a full slab. The arch cohesive zone is inserted to avoid convergence problems at the boundary. The energy used to create the arch crack is small and can be neglected. The subgrade is idealized as linear elastic.

\subsection{Effect of cemented base thickness, slab dimensions and subgrade stiffness}

In linear elastic analysis of pavement structures, the layer thickness is increased for increasing load levels, to ensure a relatively constant stress level in the subgrade soil, avoiding any plastic deformation. This approach can be questioned based on the results presented herein; as it is observed in Figure 16 that the allowable load levels in presently available guidelines [11] is twice the magnitude compared to the peak-loads found in the present study. As expected, the thickness of the cemented base layer has significant influence on the peak-load, but little influence on the post-peak response of the structure. It is also observed that the slab dimensions has influence on the normalized peak-load relationship curve.

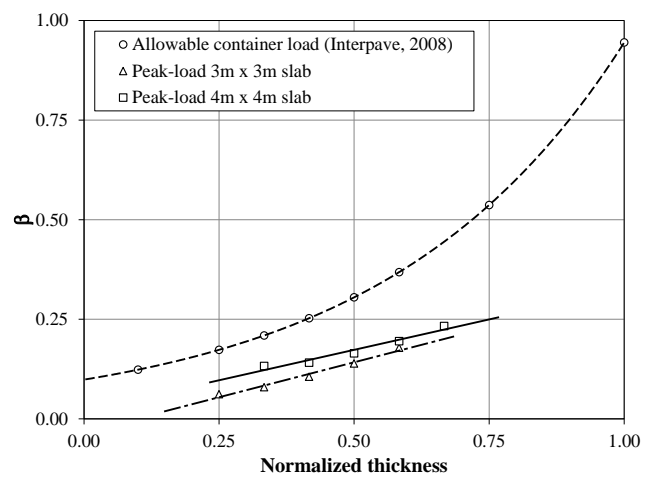

(a)

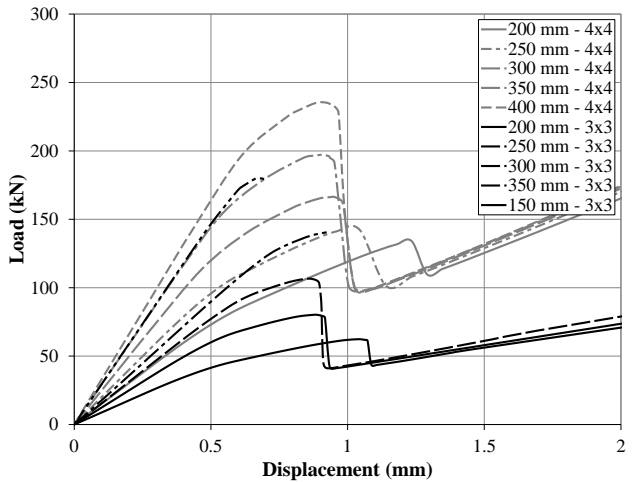

(b)

Figure 16: Influence of slab thickness varying from 150-400 mm keeping length/width constant for a $3 \times 3 \mathrm{~m}^{2}$ slab (black) and $4 \times 4 \mathrm{~m}^{2}$ slab (grey) compared to the Interpave guideline [11]; normalized peak-load $(\beta)$ versus normalized thickness curve (a) and loaddisplacement curves (b).

The stiffness- and peak-load of the structure increase with increasing thickness up to unloading. Then the structural response is mainly influenced by the slab dimension, shown in Figure 17, and the stiffness of the subgrade soil. 


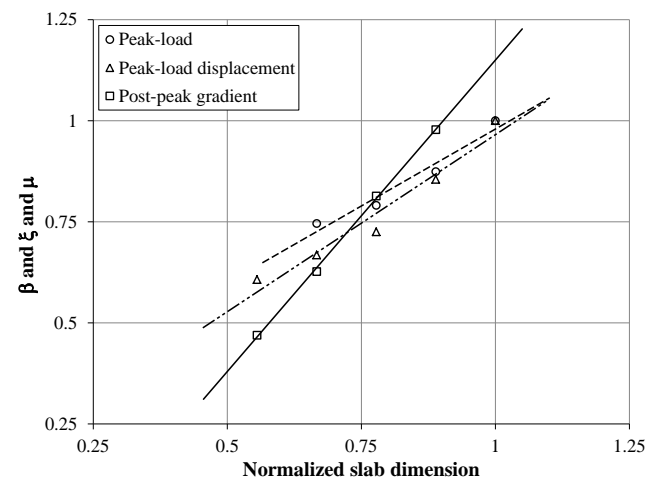

(a)

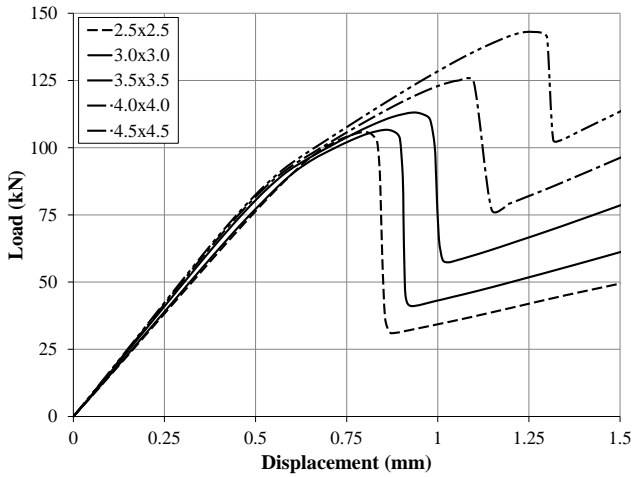

(b)

Figure 17: Influence of slab dimensions from $2.5 \times 2.5 \mathrm{~m}^{2}$ to $4.5 \times 4.5 \mathrm{~m}^{2}$, keeping thickness constant $(250 \mathrm{~mm})$; normalized peak-load $(\beta)$, peak-load displacement $(\xi)$ and post-peak gradient $(\mu)$ versus normalized slab dimension (a) and load-displacement curves (b).

It is observed from Figure 17 that the peak-load and peak-load displacement increases with increasing slab dimensions before unloading occur. It is also found that there is a significant effect from bending; with a steep increasing post-peak stiffness for increasing slab dimensions.

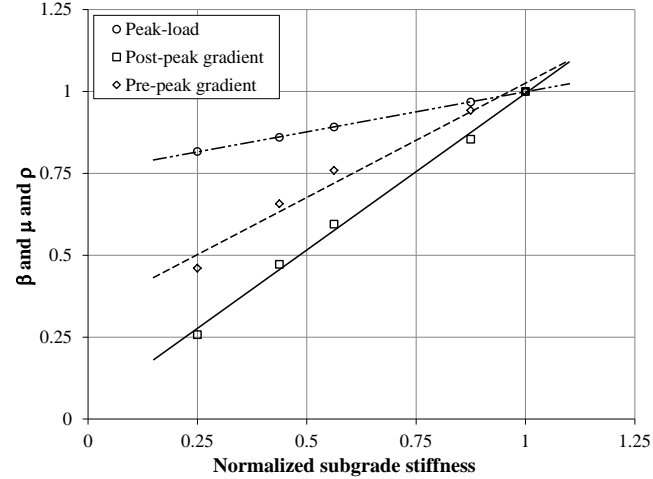

(a)

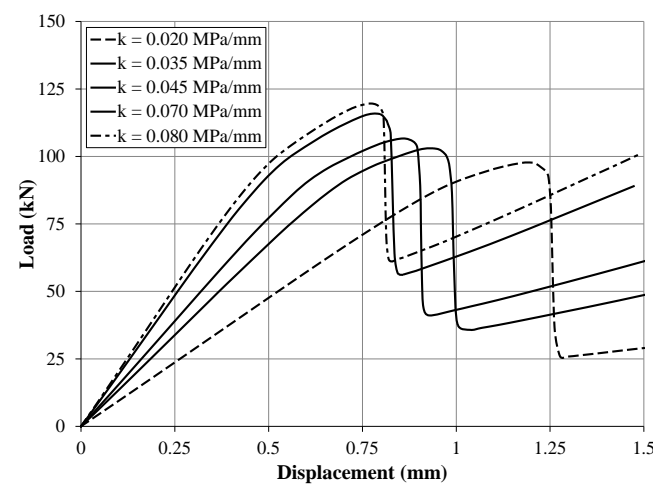

(b)

Figure 18: Influence of subgrade stiffness varying from 0.02 to $0.08 \mathrm{MPa} / \mathrm{mm}$; normalized peak-load $(\beta)$, post-peak gradient $(\mu)$ and pre-peak gradient $(\rho)$ versus normalized subgrade stiffness (a) and load-displacement curves (b).

As expected, Figure 18 shows that increasing stiffness of the subgrade 
results in increasing peak-load, post-peak and pre-peak stiffness. The difference in peak-load is $20 \%$ for the variation in subgrade stiffness evaluated, assuming that slabs is constructed on a $150 \mathrm{~mm}$ thick high quality sub-base material over subgrade soil of varying quality (california bearing ratio 5-20).

\subsection{Effect of tensile strength and fracture energy}

The softening curve depicted in Figure 3 (c) makes it obvious that the two main material parameters influencing the fracture process of the quasibrittle material is tensile strength and fracture energy. However, as shown in Figure 14 (a), the influence of tensile strength is small, both with regard to peak-load and pre- and post-peak response. This can be explained by the fact that cracking is initiated at a displacement of $0.2 \mathrm{~mm}$. Where after the response is primarily controlled by fracture energy, as shown in Figure 19 (b). It is found, that as the fracture energy decreases the material becomes more brittle. This is shown by plotting the normalized peak-load $(\beta)$ and peakload displacement $(\xi)$ against the dimensionless parameter, $(B)$, defined by Bache and Vinding [71] as:

$$
B=\frac{h}{l_{c h}}=\frac{f_{t} h}{E G_{F}}
$$

where $l_{c h}$ is the characteristic length of the material, first introduced by Hillerborg [72], $E$ is elastic stiffness, and $h$ is the slab thickness. 


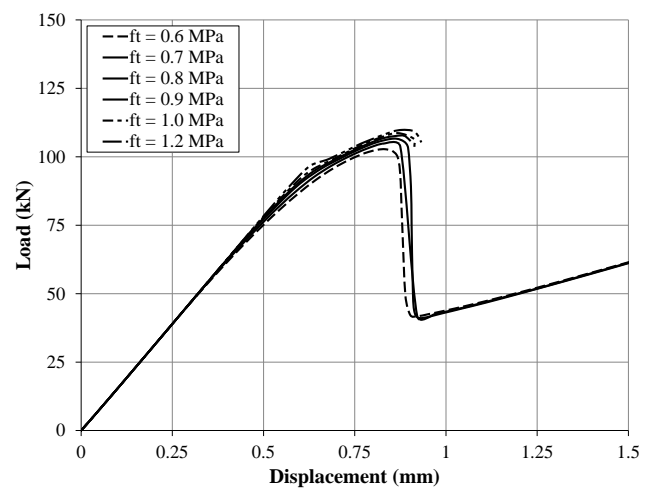

(a)

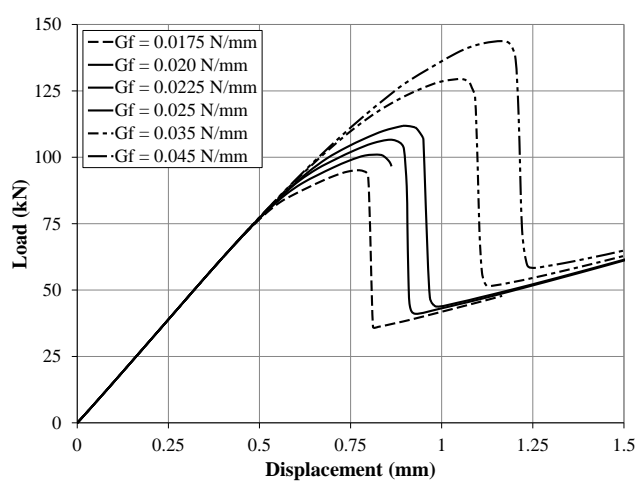

(b)

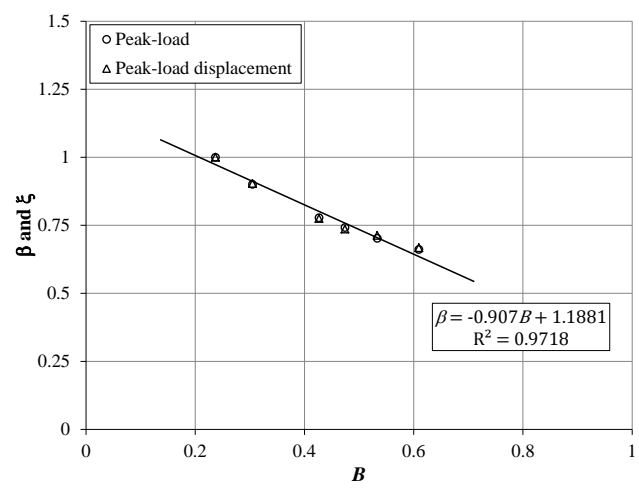

(c)

Figure 19: Influence of fracture energy; load-displacement curve for tensile strength varying from 0.6 to $1.2 \mathrm{MPa}$ keeping fracture energy constant (a), load-displacement curve for fracture energy varying from 0.0175 to $0.045 \mathrm{~N} / \mathrm{mm}$ keeping tensile strength constant (b) and normalized peak-load $(\beta)$ and peak-load displacement $(\xi)$ versus the brittleness number $(B)$ defined by Bache and Vinding [71] (c).

It is also observed from Figure 19 (c) that $\beta$ is inversely proportional to $B$, and that it may be postulated that a unique relationship exists that would allow one to determine the peak load for a particular value of $B$, given the corresponding peak load for different brittleness number [48].

\section{Influence of aggregate interlock behaviour and load position}

To extend the analysis to more realistic pavement systems, evaluating the influences from interaction with adjacent slabs and the load position, 
numerical studies of three full $\left(3 \times 3 \times 0.3 \mathrm{~m}^{3}\right)$ slabs on grade structures is carried out. The load position influence is evaluated at the interior, edge and corner of the slab; assuming two orthogonal, one length and one diagonal fracture plane in each case respectively.

The influence of variation in normal- and shear stiffness of joints is evaluated for an initial crack width, $w$, of 0.4 to $2.0 \mathrm{~mm}$, simulated by application of idealized bilinear springs as shown in Table 2 . The average strength properties for the cement bound granular mixture selected are shown in Table 1. The subgrade is idealized as linear elastic.

As expected, Figure 20 (a) shows that the load supported by the slab is higher under interior than under edge- and corner loading, with peak loads of 156, 106 and $109 \mathrm{kN}$ respectively, considering no load transfer between adjacent slabs. It is also found that that the post-peak behaviour, in the case of interior- and edge loading, are more or less similar. 


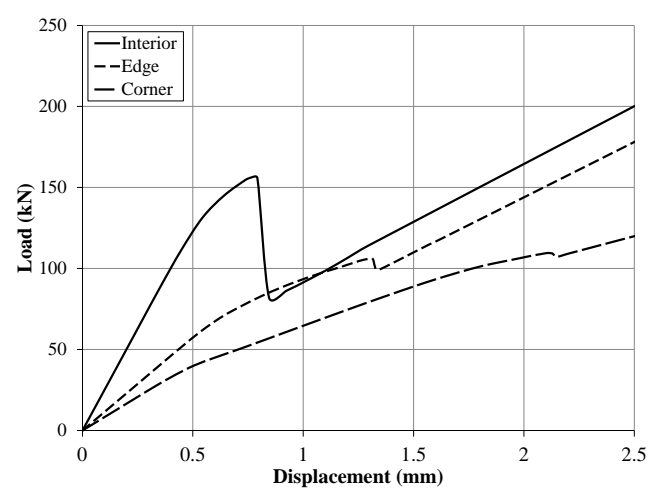

(a)

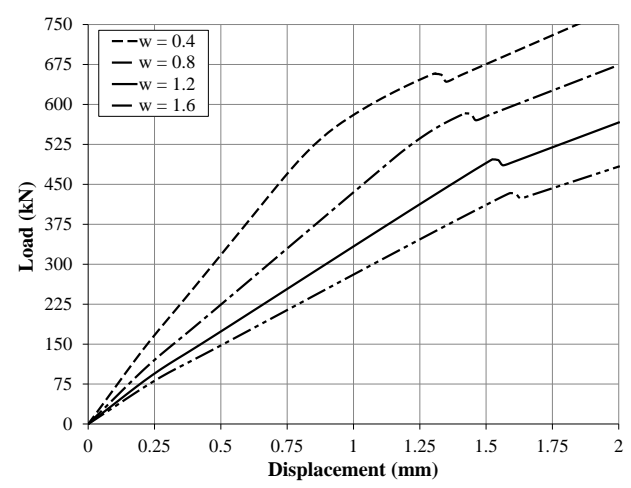

(c)

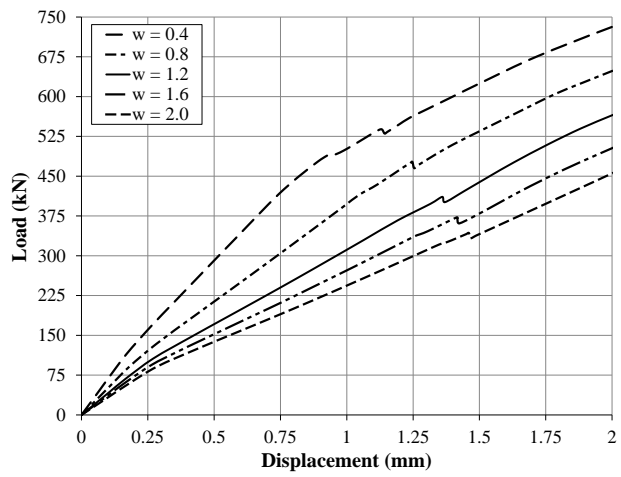

(b)

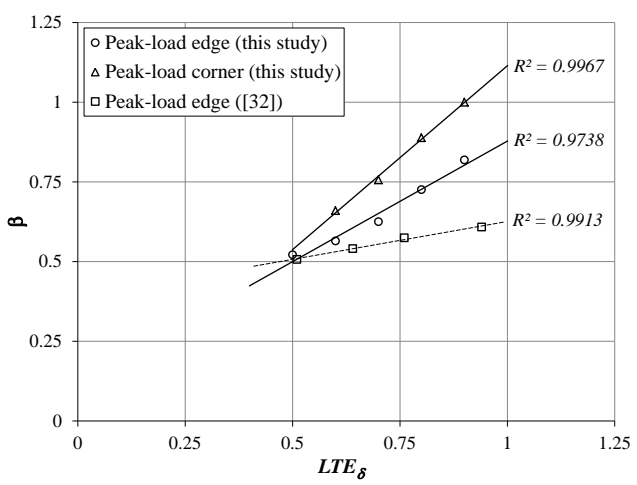

(d)

Figure 20: Evaluation of influence from load position and aggregate interlock joints; loaddisplacement curve for the three load cases (a), load-displacement curve with variation in initial joint opening for edge loading (b), corner loading (c) and normalized peak-load $(\beta)$ versus $L T E_{\delta}(\mathrm{d})$.

The initial crack width has little influence on the peak-load and peak-load displacement for interior load, whereas a pronounced increase in stiffness and peak-load can be found for edge- and corner load, shown in Figure 20 (b) and (c). Plotting the normalized peak-load $(\beta)$ versus $L T E_{\delta}$, assuming that a linear relationship exist between $w$ and $L T E_{\delta}$ [73], it can be found that $\beta$ decrease linearly with increasing $w$ as shown in Figure 20 (d). Similar trends has also been reported in numerical studies of slabs on grade by other researchers [74]. 


\section{Conclusion}

The use of a cohesive model for simulating the fracture in the cement bound granular mixtures in composite block pavement systems has been investigated by studying the main parameters that affect the responses of the pavement structure.

Comparison of numerical and experimental results for four point bending beam tests show that good agreement is obtained with the cohesive model. It is found that the cohesive model adequately describe the structural response of slabs on grade structures and that aggregate interlock behaviour can be realistically incorporated in models by idealized bilinear springs. However, tests results are limited and more testing is necessary to evaluate the fracture behaviour of cement bound granular mixtures, e.g., fracture energy and shear interaction.

Moreover, the numerical analysis of slabs on grade experiments reveal the importance of incorporating realistic subgrade soil behaviour in models. Most importantly, the shear stiffness of the soil and the plastic yield limit, as these two parameters have significantly influence on the prediction of peakload and post-peak response, respectively.

The influence of slab thickness-and dimensions proved to be important parameters. The peak-load is highly influenced by thickness, whereas slab dimensions proved to be a main controlling parameter of the post-peak response of the structure. Furthermore, it can be concluded that the fracture process is more affected by the fracture energy than the tensile strength.

The peak-loads found in the present study are significantly lower than allowable load levels given in available guidelines for composite block pavements. To extend the analysis to full evaluation of structural bearing capacity, one could include a failure criteria of the subgrade soil as shown in section 3.2. It would then be feasible with the methodology presented, to evaluate the critical load case, e.g., also including the influence of temperature loads (shrinkage).

The full slab model shows that cracking is initiated at an early stage, and that the structural response is affected by aggregate interlock behaviour. This effect is primarily important to the response of structures subjected edge- and corner loading. Moreover, it is found that the peak-load decrease linearly with increase in initial crack width.

In the present study idealized FE composite block pavement structures is developed with application of a cohesive model to describe the fracture be- 
haviour of the cement bound granular mixture. Computationally fast models are obtained, with a minimum of elements, applying the cohesive contact model in ABAQUS. Furthermore, numerical instabilities are avoided, not compromising the penalty stiffness. It is found that the idealized FE models developed adequately describe the structural response of composite block pavements subjected to heavy static loads, showing their applicability for engineering design purpose. It is envisaged that the methodology implemented can be extended to more complex and realistic problems, e.g. including also a cyclic formulation of the cohesive zone and aggregate interlock behaviour, for development of more rational failure criteria in pavement engineering in the future.

\section{Acknowledgements}

The authors would like to thank COWIfonden (grant no. C-123.03) and Innovation Fund Denmark (grant no. 1355-00060) for financial support of the research presented in this paper.

The experimental data presented in Figure 8 was provided by Austroads. The cooperation with Austroads and Dr. Richard Yao is kindly acknowledged. 


\section{Bibliography}

[1] R. Kerkhoven, G. M. Dormon, Some considerations on the California bearing ratio method for the design of flexible pavements, Shell Petroleum Company, 1953.

[2] M. A. Shahid, N. H. Thom, Performance of cement bound bases with controlled cracking, in: Rilem Proceedings, Chapman \& Hall, 1996, pp. 55-64.

[3] H. L. Theyse, M. De Beer, F. C. Rust, Overview of south african mechanistic pavement design method, Transportation Research Record (1539) (1996) 6-17.

[4] R. Yeo, Fatigue performance of cemented materials under accelerated loading: influence of vertical loading on the performance of unbound and cemented materials, no. AP-T102/08, 2008.

[5] C. Freeme, J. Maree, A. Viljoen, Mechanistic design of asphalt pavements and verification using the heavy vehicle simulator, National Institute for Transport and Road Research, 1982.

[6] J.-F. Corté, M.-T. Goux, Design of pavement structures: the french technical guide, Transportation Research Record: Journal of the Transportation Research Board 1539 (1) (1996) 116-124.

[7] G. Jameson, K. G. Sharp, R. Yeo, Cement-treated Crushed Rock Pavement Fatigue Under Accelerated Loading: The Mulgrave (Victoria) ALF Trial, 1989/1991, no. ARR229, 1992.

[8] F. Thøgersen, C. Busch, A. Henrichsen, Mechanistic design of semi-rigid pavements, Danish Road Institute. Report 138.

[9] Austroads, Pavement design: A guide to the structural design of road pavements, Austroads, 2004.

[10] AASTHO, Mechanistic-empirical design of new and rehabilitated pavement structures. NCHRP 1-37A., Transportation Research Board (2006).

[11] J. Knapton, The Structural Design of Heavy Duty Pavements for Ports and Other Industries, Interpave, 4th Edition (December 2008). 
[12] C. Busch, A. Wysokowsk, M. Cwiakala, A. Adesiyun, A. Zurawicka, A. Duszynski, L. Korusiewicz, P. Kaszub, A. Nowak, Large scale test of semi rigid pavements at test stand in zmigrod, IBDiM, COWI A/S and ECO-SERVE Thematic Network European Construction in Service of Society Report no. TW 65406/G1RT-CT-2002-05085 (2006).

[13] A. Hillerborg, M. Modeer, P.-E. Petersson, Analysis of crack formation and crack growth in concrete by means of fracture mechanics and finite elements, Cement and Concrete Research 6 (6) (1976) 773-781.

[14] M. Jirásek, Modeling of localized damage and fracture in quasibrittle materials, in: Continuous and Discontinuous Modelling of CohesiveFrictional Materials, Springer, 2001, pp. 17-29.

[15] T. Belytschko, J. Fish, B. E. Engelmann, A finite element with embedded localization zones, Computer methods in applied mechanics and engineering 70 (1) (1988) 59-89.

[16] T. Belytschko, T. Black, Elastic crack growth in finite elements with minimal remeshing, International journal for numerical methods in engineering 45 (5) (1999) 601-620.

[17] Y. Rashid, Ultimate strength analysis of prestressed concrete pressure vessels, Nuclear engineering and design 7 (4) (1968) 334-344.

[18] J. Mazars, A description of micro-and macroscale damage of concrete structures, Engineering Fracture Mechanics 25 (5) (1986) 729-737.

[19] J. Lubliner, J. Oliver, S. Oller, E. Onate, A plastic-damage model for concrete, International Journal of solids and structures 25 (3) (1989) $299-326$.

[20] K. Maekawa, J. Takemura, P. Irawan, M. Irie, Triaxial elastoplastic and fracture model for concrete, Doboku Gakkai RombunHokokushu/Proceedings of the Japan Society of Civil Engineers (460 pt 5-18) (1993) 131-138.

[21] F. Moavenzadeh, Asphalt fracture, in: Assoc Asphalt Paving Technol Proc, Vol. 36, Association of Asphalt Paving Technologists, 1967, pp. 51-79. 
[22] A. Bahgat, M. Herrin, Brittle fracture of asphalt mixtures, in: Proceedings of the Association of Asphalt Paving Technologists, Vol. 37, Association of Asphalt Paving Technologists, 1968, pp. 32-50.

[23] K. Majidzadeh, E. Kauffmann, D. Ramsamooj, Application of fracture mechanics in the analysis of pavement fatigue, in: Association of Asphalt Paving Technologists Proc, Vol. 40, 1971.

[24] D. V. Ramsamooj, K. Majidzadeh, E. Kauffmann, The analysis and design of the flexibility of pavements, in: Presented at the Third International Conference on the Structural Design of Asphalt Pavements, Grosvenor House, Park Lane, London, England, Sept. 11-15, 1972., Vol. 1, 1972.

[25] Y. Salam, C. Monismith, Fracture characteristics of asphalt concrete, Asphalt Paving Technology 41 (1972) 215-256.

[26] A. Abdulshafi, K. Majidzadeh, J-integral and cyclic plasticity approach to fatigue and fracture of asphaltic mixtures, Transportation Research Record (1034).

[27] K. W. Kim, H. El Hussein, Effect of differential thermal contraction on fracture toughness of asphalt materials at low temperatures (with discussion), Journal of the Association of Asphalt Paving Technologists 64 .

[28] M. Jacobs, P. Hopman, A. Molenaar, Application of fracture mechanics principles to analyze cracking in asphalt concrete, Journal of the Association of Asphalt Paving Technologists 65.

[29] A. Bhurke, E. Shin, L. Drzal, Fracture morphology and fracture toughness measurement of polymer-modified asphalt concrete, Transportation Research Record: Journal of the Transportation Research Board (1590) (1997) 23-33.

[30] Y.-S. Jenq, J.-D. Perng, Analysis of crack propagation in asphalt concrete using cohesive crack model, no. 1317, 1991.

[31] Y.-S. Jenq, C.-J. Liaw, P. Lieu, Analysis of crack resistance of asphalt concrete overlays - a fracture mechanics approach, Transportation Research Record: Journal of the Transportation Research Board (1388) (1993) 160-166. 
[32] J. B. Soares, F. Freitas, D. H. Allen, Crack modeling of asphaltic mixtures considering heterogeneity of the material, Transp. Res. Rec 1832 (2003) 113-120.

[33] G. H. Paulino, S. H. Song, W. G. Buttlar, Cohesive zone modeling of fracture in asphalt concrete, in: Proceedings of the 5th International RILEM Conference-Cracking in Pavements: Mitigation, Risk Assessment, and Preservation, Limoges, France, 2004, pp. 63-70.

[34] M. P. Wagoner, W. G. Buttlar, G. H. Paulino, Development of a singleedge notched beam test for asphalt concrete mixtures, Journal of Testing and Evaluation 33 (6) (2005) 452.

[35] S. H. Song, G. H. Paulino, W. G. Buttlar, Simulation of crack propagation in asphalt concrete using an intrinsic cohesive zone model, Journal of Engineering Mechanics 132 (11) (2006) 1215-1223.

[36] J. Baek, I. Al-Qadi, Finite element method modeling of reflective cracking initiation and propagation: Investigation of the effect of steel reinforcement interlayer on retarding reflective cracking in hot-mix asphalt overlay, Transportation Research Record: Journal of the Transportation Research Board (1949) (2006) 32-42.

[37] H. Kim, M. P. Wagoner, W. G. Buttlar, Numerical fracture analysis on the specimen size dependency of asphalt concrete using a cohesive softening model, Construction and Building Materials 23 (5) (2009) 21122120 .

[38] L. T. Souza, Y.-R. Kim, F. V. Souza, L. S. Castro, Experimental testing and finite-element modeling to evaluate the effects of aggregate angularity on bituminous mixture performance, Journal of Materials in Civil Engineering 24 (3) (2012) 249-258.

[39] G. Zeng, X. Yang, A. Yin, F. Bai, G. Zeng, Simulation of damage evolution and crack propagation in three-point bending pre-cracked asphalt mixture beam, Construction and Building Materials 55 (2014) 323-332. doi:10.1016/j.conbuildmat.2014.01.058.

[40] A. M. Ioannides, Fracture mechanics in pavement engineering: The specimen-size effect, Transportation Research Record (1568) (1997) 10. 
[41] A. M. Ioannides, S. Sengupta, Crack propagation in portland cement concrete beams: Implications for pavement design, Transportation Research Record 1853 (2003) 110-120.

[42] A. M. Ioannides, J. Peng, J. R. Swindler Jr, Abaqus model for pcc slab cracking, International Journal of Pavement Engineering 7 (4) (2006) 311-321.

[43] J. Roesler, G. H. Paulino, K. Park, C. Gaedicke, Concrete fracture prediction using bilinear softening, Cement and Concrete Composites 29 (4) (2007) 300-312. doi:10.1016/j.cemconcomp.2006.12.002.

[44] F. Evangelista, J. Roesler, G. Paulino, Numerical simulations of fracture resistance of functionally graded concrete materials, Transportation Reserach Record 2113 (2113) (2009) 122-131. doi:10.3141/2113-15.

[45] K. Park, G. H. Paulino, J. Roesler, Cohesive fracture model for functionally graded fiber reinforced concrete, Cement and Concrete Research 40 (6) (2010) 956-965.

[46] C. Gaedicke, J. Roesler, Fracture-based method to determine the flexural load capacity of concrete slabs, FAA COE Rep (31).

[47] C. Gaedicke, J. Roesler, F. Evangelista, Three-dimensional cohesive crack model prediction of the flexural capacity of concrete slabs on soil, Engineering Fracture Mechanics 94 (2012) 1-12.

[48] T. W. Aure, A. M. Ioannides, Numerical analysis of fracture process in pavement slabs, Canadian Journal of Civil Engineering 39 (5) (2012) 506-514. doi:10.1139/L2012-020.

[49] F. Evangelista, J. R. Roesler, S. P. Proença, Three-dimensional cohesive zone model for fracture of cementitious materials based on the thermodynamics of irreversible processes, Engineering Fracture Mechanics 97 (2013) 261-280.

[50] ABAQUS, Analysis users manual, Version 6.13-1, Dessault Systems, Providence, R.I. (2013).

[51] A. Meda, G. A. Plizzari, P. Riva, Fracture behavior of sfrc slabs on grade, Materials and StructuresS 37 (270) (2004) 405-411. doi:10.1617/14093. 
[52] M. Huurman, L. J. M. Houben, A. W. M. Kok, Development of a threedimensional finite element model for concrete block pavements, in: Proceedings Fourth International Conference on Concrete Block Paving, 1992, pp. 89-98.

[53] A. Molenaar, H. Moll, L. Houben, Structural model for concrete block pavement, no. 954, 1984.

[54] British Standards Institution - Hydraulically bound mixtures. Specifications. Cement bound granular mixtures, BS EN 14227-1:2013 (2013).

[55] D. Y. Wang, J. H. Liu, Numerical simulation of a crack in the cement stabilized stone using cohesive zone models, Proceedings of SPIE - the International Society for Optical Engineering 7375 (2008) -. doi:10.1117/12.839044.

[56] E. Heymsfield, R. E. Wahl, W. Hodo, Development of a damage model for stabilized soil layers subjected to repetitive aircraft loadings, Proceedings of the 2006 Airfield and Highway Pavement Specialty Conference 2006 (2006) 260-271.

[57] Z. Wu, Z. Zhang, X. Yang, X. Chen, Finite element model for rutting prediction of flexible pavement with cementitiously stabilized base-subbase, Transportation Research Record (2226) (2011) 104-110. doi:10.3141/2226-11.

[58] Hilsdorf, Brameshuber, Code-type formulation of fracture mechanics concepts for concrete, International Journal of Fracture 51 (1) (1991) 61-72. doi:10.1007/BF00020853.

[59] Z. P. Bazant, P. Gambarova, Rough cracks in reinforced concrete, ASCE J Struct Div 106 (4) (1980) 819-842.

[60] P. Gambarova, C. Karakoç, A new approach to the analysis of the confinement role in regularly cracked concrete elements, in: Transactions of the 7. international conference on structural mechanics in reactor technology. Vol. H, 1983.

[61] J. C. Walraven, H. W. Reinhardt, Theory and experiments on the mechanical behaviour of cracks in plain and reinforced concrete subjected to shear loading., Heron 26 (1). 
[62] J. C. Walraven, Fundamental analysis of aggregate interlock, Journal of The Structural Division-ASCE 107 (11) (1981) 2245-2270.

[63] B. Li, Contact density model for stress transfer across cracks in concrete, Journal of the Faculty of Engineering, the University of Tokyo (1) (1989) 9-52.

[64] E. Winkler, Die lehre von der elasticitaet und festigkeit, 1868.

[65] J. Maree, Aspects of the design and behaviour of pavements with granular base layers, Ph.D. thesis, Department of Civil Engineering, University of Pretoria (1982).

[66] Swiss Association of Road and Traffic Experts - Geotechnical investigations and studies: Geotechnical soil parameters, SN 670010b (1998).

[67] E. Riks, An incremental approach to the solution of snapping and buckling problems, International Journal of Solids and Structures 15 (7) (1979) 529-551.

[68] R. Yeo, The development and evaluation of protocols for the laboratory characterisation of cemented materials, no. AP-T101/08, 2008.

[69] C. Busch, A. Adesiyun, Large scale testing of semi rigid pavements, in: Proceedings of the Second International Conference of Transport Research Arena Europe (TRA) 2008, Lubljana, Slovenia, 2008.

[70] C. Busch, Incremental-recursive modeling of performance for cement bound base layers, in: Proceedings of the Third International Confrence on Accelerated Pavement Testing (APT) 2008, Madrid, Spain, 2008.

[71] H. Bache, I. Vinding, C. T. Oplysningskontor., CtO., Beton-teknik. Brudmekanik i design af betonbelaegninger, 1990.

[72] A. Hillerborg, The theoretical basis of a method to determine the fracture energyg $f$ of concrete, Materials and structures 18 (4) (1985) 291296.

[73] W. G. Davids, J. P. Mahoney, Experimental verification of rigid pavement joint load transfer modeling with everfe, Transportation Research Record: Journal of the Transportation Research Board 1684 (1) (1999) 81-89. 
[74] T. W. Aure, A. M. Ioannides, Fracture analysis of aggregate interlock jointed slabs-on-grade, Construction and Building Materials 77 (0) (2015) 340 - 348. doi:http://dx.doi.org/10.1016/j.conbuildmat.2014.12.086. 